anxiety" received a bromide mixture, but the man with tonsillitis was more fortunate; he was given "appropriate treatment," apparently because he was accommodating enough to have "a normal ailment," whatever that means. So long as " adequately physical disorder" continues to be regarded as more "actual" and more in need of "appropriate treatment" than psychoneurotic illness, "the extent of neurosis" will remain considerably greater than it need be.-I am, etc.,

$$
\text { Glasgow. }
$$

D. Yellowlees.

\section{Neurosis in Industry}

SIR,-Dr. Russel Fraser's report, The Incidence of Neurosis among Factory Workers, is of considerable interest, and the number of workers investigated-3,000-ensures reasonable sampling of the population involved. I recall that in 1938 I completed a smaller survey of an out-patient medical dispensary in Glasgow where most patients were industrial workers. Over 300 people were examined and treated at that time, and it was found that $11 \%$ of them (men and women mixed) were suffering from what I regarded as primary psychogenic neurosis. This approximates very nearly to Dr. Russel Fraser's figures of $10 \%$ men and $13 \%$ women found in 1947 in factory workers.

It is of interest to note that the war stresses made little difference between the figures I gave in 1938 and those given now in 1947. This helps us in our evaluation of the factors causing the neuroses, and some of us have seen many swings of opinion between heredity, predisposition, and environment as causal factors. The conclusion which arises from comparison of the figures quoted suggests that environment or working conditions have only a minor role in such causation.-I am, etc.,

North Shields, Northumberland.

Charles Shearer.

\section{Divorce after Temporary Insanity}

SIR,-Your medico-legal correspondent in the issue of July 26 (p. 154) gives a most interesting description of the anomalies in Herbert's (Divorce) Act revealed by the recent case of Whitley v. Whitley. However, the following statement of your correspondent appears to contradict some of his other comments : "If a patient starts his treatment as a temporary patient under the Mental Treatment Act and then changes to voluntary status he does not come within the Act, and the partner cannot have a divorce for insanity." Such a change of status in fact does not prohibit the granting of a decree, provided that the strict letter of the law is observed in regard to the original detention of the patient on temporary status, and which apparently was not so in the case of Whitley $\mathrm{v}$. Whitley, in that the visiting committee failed to sign an order for the patient's detention within one month of the patient's admission to hospital.

Your medico-legal correspondent's plea for a revision of Herbert's Act so as to bring its provisions more into line with common sense is emphasized by the features of the case Williams v. Williams (1946), in that the Williams case illustrates the varying degree of importance which the Act attaches to the detention factor in different stages of a patient's treatment. In the Williams case the respondent had been continuously detained in a mental hospital under a reception order for five years prior to the presentation of the petition for divorce, but subsequently the respondent was discharged from hospital under Section 79 (1890), and at the time of the hearing of the case was not under any institutional care. The medical evidence was that at the time of being discharged from hospital the respondent was a person incurably of unsound mind, and a decree nisi was granted, notwithstanding the fact that the respondent then, from the legal aspect, enjoyed full civic liberty.

Admittedly the Williams case differs from the Whitley case described by your medico-legal correspondent in that the respondent had been detained in the strict legal sense, but it is surely a cumbersome law which lays such emphasis on the importance of the initial treatment of the respondent being accompanied by detention, and which apparently regards detention as an irrelevant factor at the very time when the respondent's incurability calls for sccial readjustment.-I am, etc.,

\section{The Lazy Eye}

SIR,-Dr. William Moodie in his letter on the lazy eye (Aug. 23 , p. 310 ) lays himself open to certain obvious criticisms both of his facts and of his argument. It is difficult to discuss the facts in the brief compass of a letter; but, in general, the proper use of an occluder is for the purpose of overcoming amblyopia or a false projection system of abnormal retinal correspondences. The expression " a lazy eye" is a convenient translation from medical jargon intended to make the position intelligible to laymen, and particularly to the patient's parents. Like all such conventional translations it is an analogy, and the analogy must not be overstrained.

Let us assume the expression means an amblyopic eye, as it usually does. Amblyopia in children, usually associated with squint, is generally due to a process of active suppression of the visual images of the amblyopic eye, with the formation of a central scotoma, and a depression of central vision which may be extreme-e.g., to less than 6/60. Dr. Moodie begs the question by stating the condition " is nearly always optical in origin." It depends upon what is meant by the expression "optical."

Once amblyopia of this kind is established, the only means of cure is by compelling the child to use the amblyopic eye; and this can only satisfactorily be done by completely covering the other eye. In favourable cases recovery of visual acuity to $6 / 6$ may result in a short time. But if treatment is withheld the amblyopia becomes in time permanent and irreversible; it is rare to achieve much success in children aged 10 years; and in adult life the total loss of the useful eye is rarely if ever followed by any noticeable improvement in the amblyopia of the survivor.

Does Dr. Moodie seriously suggest then that these amblyopic children should be allowed to grow up with one useful eye when there is a reasonable chance of having two ? Of course occlusion means some interference with school work for a time; the greater the degree of amblyopia, the greater the interference; but this is a small price to pay for the chance of recovery of useful sight in an eye otherwise doomed to lifelong uselessness as regards central vision. The answer is early diagnosis of amblyopia and early efficient treatment (which need not be unduly lengthy), not the abolition of occlusion.

There seems to be some danger of confusion between those cases with normal binocular vision who are naturally lefthanded who show nervous disturbances if forced to use the right hand, and cases of squint with amblyopia in whom binocular vision has already broken down. It must be remembered too that psychological disturbances are sometimes a factor in the production of a squint, and so is uncorrected hypermetropia; but, if the squint results in a threat of amblyopia and occlusion is prescribed, it is not rational to blame the psychological disturbances upon the treatment. This is to put the cart before the horse.

Dr. Moodie's claim that the lazy eye " is nearly always optical in origin, often a hypermetropia," is totally misleading and quite unjustifiable, and his suggestion that " the rational treatment is optical" similarly begs the question. The rational treatment is occlusion; whether this is an "optical " treatment or not it is difficult to say. If Dr. Moodie means to imply that all cases of amblyopia in hypermetropic eyes-or even a majority of them-could be cured simply by the provision of suitable correcting lenses, then the answer is that experience shows complete failure can be expected in about $75 \%$ of cases unless occlusion is also employed.-I am, etc.,

$$
\text { Lincoln. }
$$

\section{Allan H. Briggs.}

\section{Contact Lenses}

SIR,- - It seems possible that the article on contact lenses by Dr. C. G. Kay Sharp (Aug. 16, p. 261) may give a too optimistic impression to the profession about the indications for fitting these lenses. How many of the patients wear the lens for which they have paid a tidy sum of money will never be known, for when we have made a mistake over a purchase we do not always admit it lest we should be criticized for extravagance.

While all are agreed that these lenses serve a useful purpose in many cases, it would be a mistake to think that any ametrope may wear them. A lens worn inside the eyelids constitutes a foreign body. With perfect grinding the irritation from this 